\title{
EFISIENSI REGENERASI IN VITRO MELALUI ORGANOGENESIS EMPAT VARIETAS KEDELAI (Glycine max [L].Merr.) DARI EKSPLAN BIJI YANG DIKECAMBAHKAN ATAU DIIMBIBISIKAN
}

\author{
Ria Aprilenta, Fitri Yelli, Setyo Dwi Utomo \& Akari Edy \\ Jurusan Agroteknologi, Fakultas Pertanian Universitas Lampung \\ Jl.Prof. Soemantri Brodjonegoro, No.1, Bandar Lampung 35145 \\ E-mail: Joiceaprilenta@gmail.com
}

\begin{abstract}
ABSTRAK
Penelitian ini bertujuan mengetahui pengaruh perlakuan eksplan biji yang dikecambahkan atau diimbibisikan (prakultur) terhadap efisiensi regenerasi in vitro empat varietas kedelai (Glycine max (L).Merr.) melalui organogenesis. Penelitian dilakukan di Laboratorium Kultur Jaringan, Fakultas Pertanian, Universitas Lampung, dari bulan Maret 2013 sampai dengan Mei 2013. Percobaan disusun dalam rancangan acak kelompok yang terdiri atas 5 ulangan. Perlakuan disusun secara faktorial (4x2) dengan faktor pertama adalah varietas kedelai sebagai eksplan (Grobogan, Argomulyo, Tanggamus, dan Ijen) dan faktor kedua adalah perlakuan pra-kultur (imbibisi atau pengecambahan). Setiap satuan percobaan terdiri atas empat eksplan yang dikulturkan dalam satu botol. Hasil penelitian menunjukkan bahwa perlakuan pra-kultur berpengaruh terhadap persentase eksplan yang menghasilkan tunas adventif (PEMTA) dan rata-rata jumlah tunas adventif per eksplan (RJTA). Sedangkan perlakuan varietas dan interaksi hanya berpengaruh pada PEMTA tetapi tidak berpengaruh pada RJTA. Pada perlakuan imbibisi, PEMTA varietas Ijen lebih tinggi daripada Grobogan, Argomulyo, dan Tanggamus. Pada perlakuan pengecambahan, PEMTA varietas Ijen lebih tinggi daripada Argomulyo namun tidak berbeda dengan Tanggamus dan Grobogan. Jika menggunakan varietas Ijen dan Argomulyo, PEMTA perlakuan imbibisi lebih tinggi daripada pengecambahan. RJTA perlakuan pra-kultur imbibisi 20 jam (19,5 tunas per eksplan) lebih tinggi daripada perlakuan kecambah 6 hari $(9,63$ tunas per eksplan). Selain itu, media pengakaran $1 / 2$ MS tanpa NAA lebih baik dalam membentuk akar fungsional daripada $1 \frac{1}{2}$ MS yang mengandung NAA $0,5 \mathrm{mg} / \mathrm{l}$.
\end{abstract}

Kata kunci: imbibisi, kotiledon, kedelai, organogenesis, pengecambahan, pengakaran.

\section{PENDAHULUAN}

Kedelai (Glycine max (L.) Merr.) merupakan komoditas pangan sumber utama protein nabati dan minyak nabati yang sangat penting di dunia. Di Indonesia, kebutuhan akan kedelai terus meningkat setiap tahunnya. Berdasarkan data tahun 2011, produksi dalam negeri sebesar $\pm 851,29$ ribu ton biji kering atau hanya mencukupi $\pm 37,01 \%$ dari kebutuhan, sisanya $\pm 64 \%$ diimpor dari negara lain (Badan Pusat Statistik, 2012). Oleh karena itu, perlu upaya peningkatan produksi kedelai dalam negeri. Salah satu upaya yang perlu dilakukan melalui penggunaan varietas unggul. Beberapa cara dapat dilakukan untuk memperoleh varietas unggul. Salah satunya ialah melalui rekayasa genetika. Keberhasilan transformasi genetik untuk memperoleh tanaman transgenik sangat ditentukan oleh teknik regenerasi in vitro (Pardal, 2002). Regenerasi in vitro kedelai dapat ditempuh melalui jalur embriogenesis somatik dan organogenesis. Regenerasi in vitro berfungsi untuk meregenerasikan tanaman transgenik dari sel atau jaringan transgenik (Utomo et al., 2010).Protokol regenerasi in vitro kedelai yang efisien digunakan dalam transformasi genetik sehingga diharapkan memperbesar efisiensi transformasi genetik kedelai. Utomo et al. (2010) melaporkan prosedur regenerasi in vitro dari eksplan buku kotiledon enam varietas kedelai (Wilis, Sinabung, Anjasmoro, Kaba, Seluwah, dan Sibayak) melalui organogenesis. Eksplan buku kotiledon diperoleh dari benih yang dikecambahkan selama 5-6 hari. Proporsi eksplan yang menghasilkan tunas berkisar $43-100 \%$. Rata-rata jumlah tunas per ekplan berkisar antara 7-36 tunas per eksplan. Prosedur transformasi genetik kedelai dimodifikasi oleh Paz et al. (2006) dengan menggunakan eksplan buku kotiledon (cotyledonary nodes) dari benih masak. Benih masak tersebut diperoleh melalui perlakuan pra-kultur berupa pengecambahan 6 hari, sedangkan benih masak lainnya 
diperoleh dengan perlakuan imbibisi semalam. Prosedur ini juga yang dilakukan oleh Safitri (2013) yang menerapkan lima varietas kedelai (Anjasmoro, Kaba, Willis, Sinabung, dan Seulawah) pada masing-masing perlakuan pra-kultur (imbibisi dan pengecambahan). Rata-rata jumlah tunas adventif per eksplan perlakuan imbibisi yaitu 15,4 tunas per eksplan lebih tinggi daripada perlakuan pengecambahan 6 hari yaitu 12,9 tunas per eksplan.

Prosedur regenerasi in vitro kedelai dengan perlakuan pra-kultur imbibisi belum banyak digunakan. Namun, perlakuan imbibisi memiliki kelebihan dalam efisiensi waktu karna membutuhkan waktu yang lebih singkat dibandingkan perlakuan pengecambahan. Penelitian ini dilakukan untuk mengetahui pengaruh perlakuan pra-kultur (imbibisi atau pengecambahan) terhadap efisiensi regenerasi in vitro empat varietas kedelai.

\section{BAHAN DAN METODE}

Penelitian dilaksanakan di Laboratorium Kultur Jaringan / Ilmu Tanaman Fakultas Pertanian Universitas Lampung dari Maret 2013 sampai dengan Mei 2013. Percobaan menggunakan menggunakan rancangan acak kelompok yang disusun dalam faktorial $4 \times 2$. Faktor pertama adalah varietas kedelai sebagai sumber eksplan (Grobogan, Argomulyo, Tanggamus, dan Ijen). Faktor kedua adalah perlakuan pra-kultur (imbibisi 20 jam dan pengecambahan 6 hari). Setiap satuan percobaan terdiri atas empat eksplan yang dikulturkan dalam satu botol dan setiap perlakuan diulang 5 kali.

Benih kedelai disterilkan dengan menggunakan gas klorin yaitu dengan menaruh benih kedelai pada cawan petri terbuka yang ditempatkan berjejer dalam desikator. Gas klorin diproduksi di dalam desikator dengan cara menambahkan tetes demi tetes $3,3 \mathrm{ml} \mathrm{HCl}$ $12 \mathrm{~N}$ ke permukaan dinding bagian dalam gelas piala yang telah berisi $100 \mathrm{ml}$ Bayclin yang berbahan aktif $\mathrm{NaClO} 5,25 \%$. Desikator kemudian ditutup rapat dengan menambahkan vaselin disekitar pinggiran tutup kemudian dibalut dengan plastik wrap dan dibiarkan selama $2 \mathrm{x}$ 24 jam. Setelah itu, desikator dibuka dengan cara menggeser tutup desikator ke arah samping dan segera diikuti dengan penutupan cawan petri berisi benih kedelai yang sudah steril. Untuk menurunkan konsentrasi gas klorin, cawan petri kemudian dikeluarkan dari desikatordan segera ditempatkan dalam laminar air flow hood selama 30 menit.

Pada perlakuan pra-kultur imbibisi, benih 4 varietas yang telah melalui proses sterilisasi masingmasing sebanyak 25-30 benih dimasukkan ke dalam erlenmeyer yang berisi air steril sehingga benih-benih tersebut terendam sepenuhnya. Perendaman benihbenih tersebut dilakukan selama 20 jam pada suhu $24 \pm$ $2^{\circ} \mathrm{C}$ dengan 16 jam terang dan 8 jam gelap. Sedangkan pada perlakuan prakultur pengecambahan, masingmasing keempat varietas kedelai yang telah disterilisasi kemudian ditanam ke dalam medium MS (MS tanpa zat pengatur tumbuh)yang mengandung $2 \%$ sukrosa dan dipadatkan dengan $0,8 \%$ agar. Masing-masing benih kedelai yang ditanam adalah 4-5 benih per botol kemudian dikecambahkan selama 5-6 hari pada suhu $24 \pm 2^{\circ} \mathrm{C}$ dengan 16 jam terang dan 8 jam gelap.

Setelah proses perlakuan pra-kultur selesai, pengkulturan pada media inisiasi tunas dapat dilakukan dari sumber eksplan yang telah melalui proses tersebut. Pada perlakuan pra-kultur imbibisi, air yang terdapat didalam erlenmeyer yang berisi benih dibuang kemudian dilanjutkan dengan membelah benih secara vertikal menjadi dua bagian kotiledon. Pucuk poros embrio di atas buku kotiledon dibuang dan selanjutnya dibuat 5-7 goresan sepanjang 2-3 mm sejajar dengan poros embrio pada buku kotiledon menggunakan pisau skapel no. 15 . Eksplan buku kotiledon dari kecambah yang berumur 20 jam tersebut dikulturkan pada media inisiasi tunas (MS) yang mengandung benzilamino purin (BAP) 0,75 mg l-1. Penyiapan eksplan dari perlakuan pra-kultur pengecambahan 6 hari yakni dengan memisahkan kotiledon dari akarnya dengan cara memotong hipokotil 3-5 mm di bawah buku kotiledon. Dua kotiledon dipisahkan dengan cara membelah vertikal sepanjang hipokotil kemudian pucuk poros embrio di atas buku kotiledon dibuang. Selanjutnya dibuat 5-7 goresan sepanjang 2-3 mm sejajar dengan poros embrio pada buku kotiledon.

Setelah berumur 40 hari setelah tanam (hst), tunas adventif yang tumbuh pada setiap eksplan dipisahkan satu per satu. Tunas-tunas yang memiliki lebih dari 3 daun dikulturkan ke dalam medium pengakaran masingmasing 1 tunas per botol. Hal ini bertujuan agar akar yang muncul dari tunas dapat tumbuh dengan baik. Medium pengakaran yang digunakan adalah media $1 / 2$ MS dan media $1 / 2$ MS yang mengandung NAA $0,5 \mathrm{mg} 1$ ${ }^{-1}$. Masing-masing perlakuan ditanam ke dalam dua media pengakaran tersebut. Pengamatan tunas yang membentuk akar fungsional dilakukan pada umur 3 minggu setelah tanam (mst) selama di medium pengakaran.

Untuk mengetahui efisiensi regenerasi in vitro kedelai secara organogenesis melalui perlakuan prakultur, maka dilakukan pengamatan pada variabel berikut: 
(1) Persentase eksplan yang membentuk tunas adventif (PEMTA).

$$
\text { PEMTA }=\frac{\sum(\text { eksplan yang membentuk } \geq 1 \text { tunas adventif })}{\sum(\text { eksplan yang dikulturkan per satuan percobaan })} \times 100 \%
$$

(2) Rata-rata jumlah tunas adventif per eksplan (RJTA).

$$
\text { RJTA }=\frac{\left.\sum \text { (tunas adventif yang tumbuh }\right)}{\sum(\text { eksplan yang menghasilkan tunas per satuan percobaan })}
$$

(3) Proporsi tunas yang membentuk akar fungsional (PTMAF). Tunas yang mengalami perkembangan akar secara terus menerus (akar fungsional) diamati selama 3 mst untuk selanjutnya diaklimatisasi.

\section{HASIL DAN PEMBAHASAN}

Berdasarkan hasil penelitian, terlihat respon awal yang relatif berbeda dari kedua eksplan melalui perlakuan pra-kultur imbibisi atau pengecambahan. Secara visual, terdapat perbedaan warna buku kotiledon yang telah melalui perlakuan pra-kultur (Gambar 1a dan 1b). Pada perlakuan imbibisi selama 20 jam, benih mengalami perbesaran dua kali lipat dari ukuran benih semula dan muncul hipokotil yang keluar dari poros embrio. Sedangkan pada benih yang diperlakukan kecambah 6 hari mengalami pertumbuhan hipokotil yang terus-menerus dan adanya perubahan warna menjadi hijau pada bagian buku kotiledon. Eksplan buku kotiledon selanjutnya disayat dan ditanam dalam media inisiasi tunas (Gambar 1c).

Pada penelitian ini, pengamatan efisiensi regenerasi didasarkan pada persentase eksplan yang
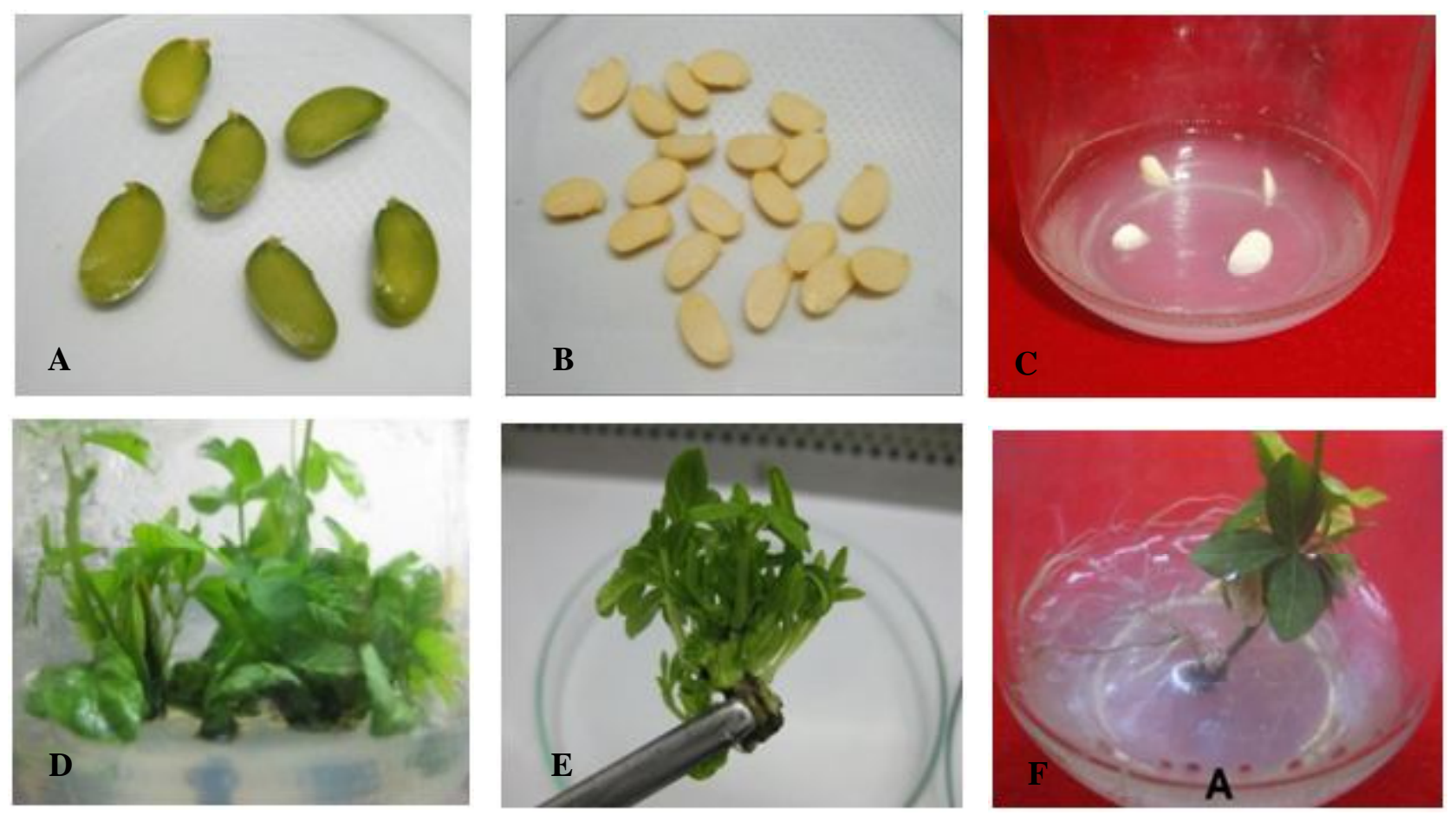

Gambar 1. Pembentukan tunas adventif kedelai secara organogenesis melalui perlakuan pra-kultur imbibisi dan pengecambahan.(A) eksplan dari benih varietas Ijen perlakuan imbibisi 20 jam, (B) eksplan dari benih varietas Grobogan perlakuan kecambah 5-6 hari, (C) eksplan perlakuan imbibisi dalam media inisiasi tunas, (D) tunas adventif varietas Tanggamus umur 40 hari setelah dikulturkan dalam media inisiasi tunas, (E) tunas adventif yang muncul pada eksplan varietas Ijen perlakuan imbibisi, (F) penampilan akar varietas Ijen pada media $1 \frac{1}{2}$ MS. 
menghasilkan tunas adventif (PEMTA) serta rata-rata jumlah tunas adventif per eksplan (RJTA). Pengamatan efisiensi regenerasi didasarkan pada pembentukkan tunas adventif karena pada umumnya tanaman transgenik kedelai yang diregenerasikan melalui organogenesis berasal dari tunas adventif, bukan tunas aksilar (Utomo, 2005). Pada umur 8 hst mulai terbentuk kalus pada beberapa eksplan dan tunas aksilar juga mulai mucul. Tunas aksilar adalah tunas yang terbentuk secara langsung dari meristem aksilar tanpa melalui fase kalus sehingga tunas tersebut terbentuk jauh lebih cepat daripada tunas adventif (Utomo et al., 2010). Tunas aksilar yang terbentuk dipotong dan dibuang. Berbeda dengan tunas aksilar, tunas adventif baru terlihat muncul setelah umur 18 hst. Tunas adventif adalah tunas yang telah membentuk $\geq 1$ daun trifoliate.
Pada umur 40 hst (Gambar 1d), dilakukan pengamatan terhadap persentase eksplan membentuk tunas adventif dan rata-rata jumlah tunas adventif per eksplan. Tunas adventif yang memiliki lebih dari 3 daun pada setiap eksplan dipisahkan satu per satu untuk selanjutnya dikulturkan ke dalam medium pengakaran masing-masing 1 tunas per botol agar akar yang muncul dari tunas dapat tumbuh dengan baik. Ada beberapa eksplan varietas Ijen dengan perlakuan pra-kultur imbibisi yang menghasilkan tunas adventif dalam jumlah banyak pada umur 40 hst (Gambar 1e).

Berdasarkan hasil analisis ragam, efisiensi regenerasi pada variabel pengamatan persentase eksplan yang menghasilkan tunas adventif (PEMTA) dipengaruhi oleh perlakuan pra-kultur, varietas, serta interaksi kedua faktor (Tabel 1). Pada perlakuan

Tabel 1. Hasil analisis ragam variabel PEMTA, dan RJTA.

\begin{tabular}{cccc}
\hline \multirow{2}{*}{ Variabel Pengamatan } & \multicolumn{3}{c}{ Perlakuan } \\
\cline { 2 - 4 } & Imbibisi atau & Varietas & PxV \\
& pengecambahan $(\mathrm{P})$ & $(\mathrm{V})$ & $*$ \\
PEMTA & $*$ & $*$ & tn \\
\hline
\end{tabular}

Keterangan: $*=$ berbeda nyata pada taraf $5 \%, \mathrm{tn}=$ tidak berbeda nyata pada taraf $5 \%$.

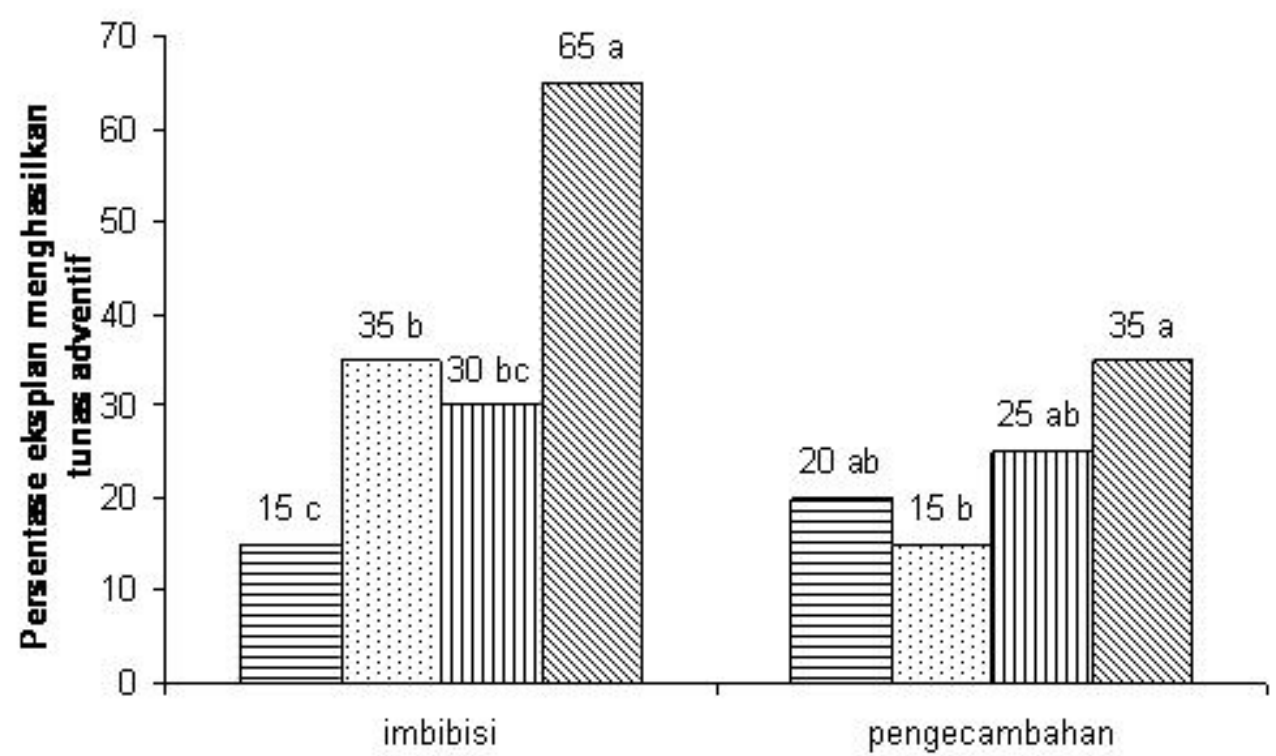

Gambar 2. Pengaruh varietas terhadap setiap perlakuan pra-kultur (imbibisi dan pengecambahan). Angka yang diikuti huruf yang sama pada setiap perlakuan varietas tidak berbeda nyata berdasarkan uji BNT5\% $(16,81)$. = Varietas Grobogan, $\square=$ Varietas Agromulyo, $\square=$ Varietas Tanggamus, $8=$ Varietas Ijen. 
imbibisi, PEMTA varietas Ijen (65\%) lebih tinggi daripada ketiga varietas lainnya (Gambar 2), sedangkan PEMTA varietas Tanggamus (30\%) tidak berbeda dengan Argomulyo (35\%) dan Grobogan (15\%). PEMTA varietas Argomulyo lebih tinggi daripada Grobogan. Pada perlakuan pengecambahan, PEMTA varietas Ijen (35\%) tidak berbeda dengan Tanggamus (25\%) dan Grobogan (20\%). PEMTA varietas Ijen lebih tinggi daripada Argomulyo (15\%). Persentase eksplan yang menghasilkan tunas adventif (PEMTA) perlakuan imbibisi dan pengecambahan berbeda pada varietas Ijen dan Argomulyo (Gambar 3). Jika menggunakan varietas Ijen, perlakuan imbibisi (65\%) lebih tinggi daripada pengecambahan (35\%). Demikian juga dengan varietas Argomulyo, perlakuan imbibisi (35\%) lebih tinggi daripada pengecambahan (15\%). Sebaliknya, PEMTA perlakuan imbibisi dan pengecambahan tidak berbeda pada perlakuan varietas Tanggamus dan Grobogan.

Hasil penelitian ini sesuai dengan hasil yang dilaporkan oleh Marveldani et al. (2007) bahwa persentase eksplan yang membentuk tunas tertinggi ditunjukkan oleh varietas Ijen yaitu sebesar 77,5\%. PEMTA tertinggi dalam penelitian ini juga ditunjukkan oleh varietas Ijen, tetapi PEMTA yang diperoleh pada varietas Ijen dengan perlakuan imbibisi dalam penelitian ini hanya sebesar $65 \%$. Hasil penelitian ini juga menunjukkan PEMTA yang relatif lebih rendah daripada Utomo et al. (2010). Eksplan yang berasal dari benih masak yang dikecambahkan selama 5-6 hari pada varietas Wilis, Sinabung, Anjasmoro, Kaba, Seulawah, dan Sibayak dilaporkan berturut-turut sebesar 94\%, $100 \%, 86 \%, 96 \%, 90 \%$, dan $81 \%$.

Berdasarkan hasil analisis ragam, pengaruh varietas dan interaksi tidak nyata, sedangkan perlakuan pra-kultur nyata terhadap rata-rata jumlah tunas per eksplan (RJTA). Perlakuan pra-kultur imbibisi lebih tinggi dibandingkan dengan perlakuan pengecambahan. Perlakuan imbibisi memiliki nilai rata-rata jumlah tunas per eksplan sebesar 19,5 tunas sedangkan perlakuan pengecambahan sebesar 9,63 tunas dari semua varietas yang dicobakan. Hasil penelitian ini sesuai dengan hasil yang dilaporkan oleh Safitri (2013) bahwa RJTA dipengaruhi oleh perlakuan pra-kultur namun tidak dipengaruhi oleh perlakuan varietas maupun interaksi kedua faktor. RJTA perlakuan imbibisi yaitu 15,4 tunas lebih tinggi daripada perlakuan pengecambahan yaitu 12,9 tunas (Tabel 2).

RJTA dalam penelitian ini setara dengan yang dilaporkan oleh Utomo et al.(2010) yang menggunakan eksplan dari benih masak yang dikecambahkan secara in vitro selama 5-6 hari. Namun, varietas yang dievaluasi adalah varietas Wilis, Sinabung, Anjasmoro, Kaba, Seulawah, dan Sibayak. RJTA yang diperoleh berkisar antara 9,3-19,7 tunas. Hasil ini hampir sama dengan RJTA yang dihasilkan pada penelitian ini berkisar antara 9,63-19,5 tunas. Menurut Pierik (1987) yang

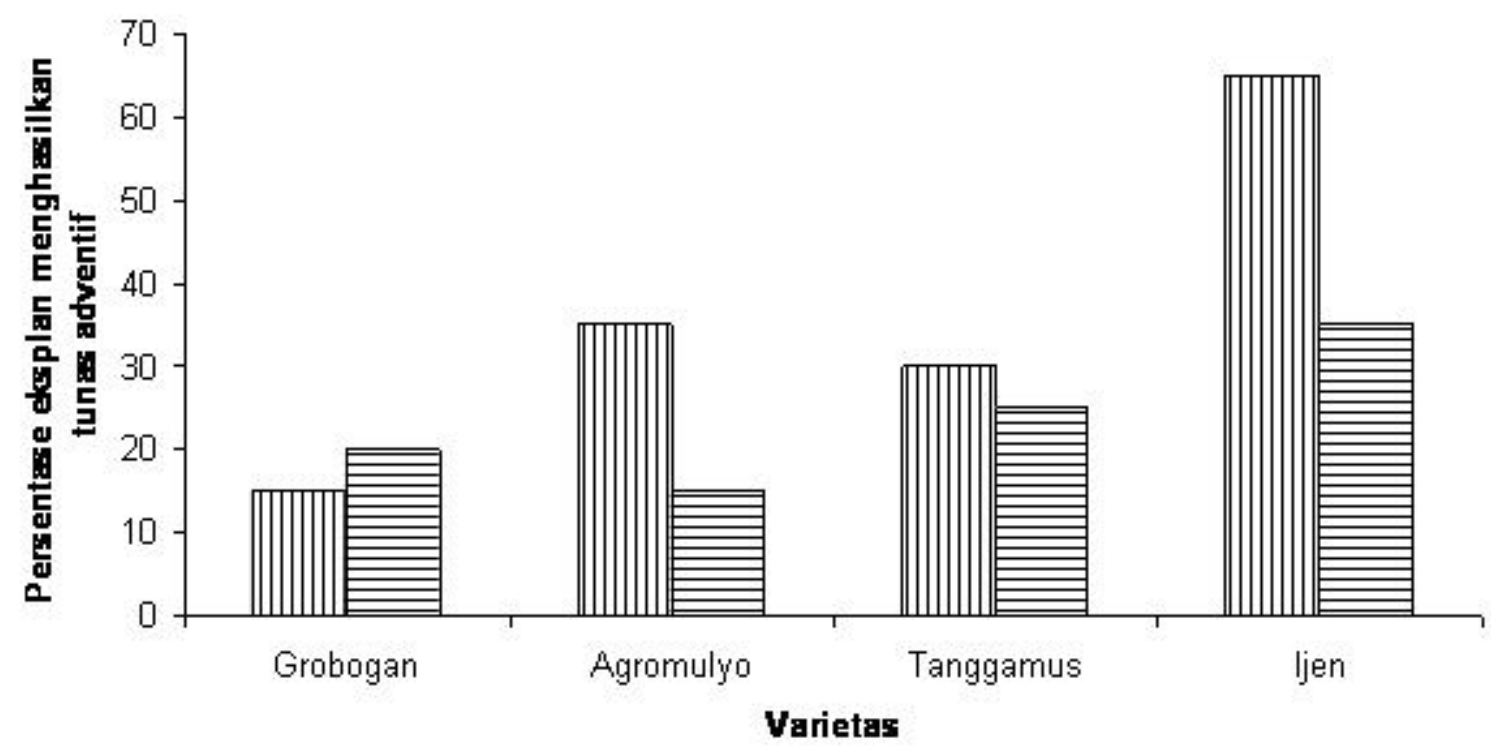

Gambar 3. Pengaruh pra-kultur terhadap setiap perlakuan varietas.Angka yang diikuti huruf yang sama padasetiap perlakuan pra-kultur tidak berbeda nyata berdasarkan uji BNT 5\% (16,81). 四=imbibisi, 曰=kecambah 
Tabel 2. Pengaruh perlakuan pra-kultur (imbibisi atau pengecambahan) terhadap rata-rata jumlah tunas adventif per eksplan (RJTA).

\begin{tabular}{cc}
\hline Perlakuan pra-kultur & Rata-rata jumlah tunas adventif per eskplan (RJTA) \\
\hline Imbibisi & $19,50 \mathrm{a}$ \\
Pengecambahan & $9,63 \mathrm{~b}$ \\
\hline
\end{tabular}

Keterangan: Angka yang diikuti huruf yang sama tidak berbeda nyata menurut uji BNT pada taraf nyata 5\%.

Tabel 3. Uji t-student taraf nyata 5\% pada persentase tunas adventif kedelai yang membentuk akar fungsional pada dua macam media pengakaran pada $3 \mathrm{mst}$.

\begin{tabular}{lcc}
\hline Media Pengakaran & Pra-kultur & Rata-rata (\%) \\
\hline $1 / 2 \mathrm{MS}$ & Imbibisi & $81,75 \mathrm{a}$ \\
$1 / 2 \mathrm{MS}$ & Kecambah & $81,00 \mathrm{a}$ \\
$1 / 2 \mathrm{MS}+$ NAA $0,5 \mathrm{mg} \mathrm{l}^{-1}$ & Imbibisi & $77,00 \mathrm{ab}$ \\
$1 / 2 \mathrm{MS}+$ NAA $0,5 \mathrm{mg} \mathrm{l}^{-1}$ & Kecambah & $67,00 \mathrm{~b}$ \\
\hline
\end{tabular}

Keterangan: Angka yang diikuti huruf yang sama tidak berbeda nyata menurut uji t-student pada taraf nyata 5\%

dikutip oleh Pardal (2002), adanya perbedaan efisiensi regenerasi in vitro tersebut disebabkan adanya perbedaan genotipe dari masing-masing varietas sehingga menyebabkan perbedaan respon regenerasi pada setiap varietas.

Pada variabel pengamatan proporsi tunas yang membentuk akar fungsional (PTMAF), perlakuan media $1 / 2$ MS tanpa NAA cenderung membentuk akar yang lebih baik dengan waktu paling cepat daripada perlakuan media $1 / 2 \mathrm{MS}+$ NAA $0,5 \mathrm{mg} \mathrm{l}^{-1}$. Pada umur $3 \mathrm{mst}$, tunas-tunas adventif yang diakarkan dalam media $1 / 2 \mathrm{MS}$ dengan NAA $0,5 \mathrm{mg}^{-1}$ tidak secara langsung membentuk akar, akan tetapi terlebih dahulu melalui pembentukan kalus sehingga akar yang terbentuk lebih lambat dibandingkan pada media $1 / 2$ MS. Hasil penelitian ini menunjukkan adanya pengaruh hormon yang ditambahkan ke dalam media terhadap model pertumbuhan akar. Karakter planlet yang ditumbuhkan dalam media $1 / 2$ MS membentuk akar yang jumlahnya banyak, berukuran relatif kecil dan panjang (Gambar 3f). Akar-akar tersebut lebih baik dalam melakukan penyerapan unsur hara dan mineral (Lestari, 2011). Berbeda dengan media $1 / 2 \mathrm{MS}$, pada media $1 / 2 \mathrm{MS}$ yang ditambahkan dengan NAA 0,5 mg/l terbentuk kalus yang menyebabkan akar yang tidak banyak, berbentuk pendek dan besar. Hal ini juga mengganggu dalam proses aklimatisasi dan penyerapan hara pada tanaman.

Berdasarkan Tabel 3, PTMAF dengan perlakuan imbibisi pada media $1 \frac{1}{2} \mathrm{MS}(81 \%)$ lebih tinggi daripada media $1 / 2$ MS+NAA $0,5 \mathrm{mg} \mathrm{l}^{-1}(67 \%)$. Namun, PTMAF perlakuan kecambah pada media $1 / 2$ MS $(81,75 \%)$ tidak berbeda dengan media $1 / 2$ MS+NAA $0,5 \mathrm{mg} \mathrm{l}^{-1}(77 \%)$. Hal ini menunjukkan bahwa media perlakuan $1 / 2$ MS lebih responsif terhadap PTMAF baik pada tunas yang berasal dari perlakuan imbibisi maupun pengecambahan.

\section{KESIMPULAN}

Perlakuan pra-kultur berpengaruh terhadap persentase eksplan yang menghasilkan tunas adventif (PEMTA) dan rata-rata jumlah tunas adventif per eksplan (RJTA). Sedangkan perlakuan varietas dan interaksi hanya berpengaruh pada PEMTA tetapi tidak berpengaruh pada RJTA.Pada perlakuan imbibisi, PEMTA varietas Ijen lebih tinggi daripada Grobogan, Argomulyo, dan Tanggamus. Pada perlakuan pengecambahan, PEMTA varietas Ijen lebih tinggi daripada Argomulyo namun tidak berbeda dengan Tanggamus dan Grobogan. Jika menggunakan varietas Ijen dan Argomulyo, PEMTA perlakuan imbibisi lebih tinggi daripada pengecambahan. RJTA perlakuan prakultur imbibisi 20 jam (19,5 tunas per eksplan) lebih tinggi daripada perlakuan kecambah 6 hari $(9,63$ tunas per eksplan). Selain itu, media pengakaran $1 \frac{1}{2} \mathrm{MS}$ tanpa NAA lebih baik dalam membentuk akar fungsional daripada $1 / 2 \mathrm{MS}$ yang mengandung NAA $0,5 \mathrm{mg} \mathrm{l}^{-1}$. 


\section{DAFTAR PUSTAKA}

Badan Pusat Statistik. 2012. Produksi kedelai indonesia. http://www.bps.go.id. Badan Pusat Statistik. Jakarta.

Lestari, Endang G. 2011. Peranan zat pengatur tumbuh dalam perbanyakan tanaman melalui kultur jaringan. AgroBiogen. 7(1):63-68.

Marveldani, M. Barmawi, dan S.D.Utomo. 2007. Regenerasi in vitro kedelai melalui organogenesis pada tiga konsentrasi benziladenin. Jurnal Agrin. 10 (1): 49-55.

Pardal, S. J. 2002. Perkembangan penelitian regenerasi dan transformasi pada tanaman kedelai. Buletin Agrobio 5:37-44.

Paz, M.M., J.C. Martinez, A.B. Kavlig, T.M. Fonger and K.Wang. 2006. Improved cotyledonary node method using an alternative explant derived from mature seed for efficient Agrobacterium-mediated soybean transformation. Plant Cell Rep. 25:206-213.
Safitri, Yesi. 2013. Pengaruh Perlakuan Pra-kultur Terhadap Efisiensi Regenerasi In Vitro Lima Varietas Kedelai (Glycine $\max (\mathrm{L}$.) Merr.). (Skripsi). Universitas Lampung. Bandar Lampung.

Salisbury, F. B., C, W. Ross. 1992. Plant Physiology 4th edition. Diterjemahkan oleh Lukman, D.R., dan Sumaryono. 1995. Fisiologi Tumbuhan Jilid 3. Institut Teknologi Bandung. Bandung. 202$209 \mathrm{hlm}$.

Utomo, S.D. 2004. Transformasi genetik lima varietas kedelai menggunakan Agrobacterium. Jurnal Agrotropika 9(2):95-101.

Utomo, S. D. 2005. Efisiensi Regenerasi In Vitro Enam Varietas Kedelai melalui Organogenesis. Jurnal Agrista. 9 (1): 83-92.

Utomo, S.D., F. Yelli, dan A. Edy. 2010. Regenerasi in vitro dari eksplan buku kotiledon enam varietas kedelai melalui organogenesis pada medium MS. Prosiding bagian II. Seminar Nasonal Sains dan Teknologi III. Universitas Lampung. Bandar Lampung. 2:433-440. 